\title{
Dermatite epidêmica por Paederus irritans em Piura, Perú, 1999, relacionada ao fenômeno El Niño
}

\author{
Epidemic dermatits by Paederus irritans in Piura, Perú at 1999, \\ related to El Niño phenomenon
}

\author{
Victor Alva-Dávalos', Victor Alberto Laguna-Torres², A. Huamán', \\ R. Olivos ${ }^{1}$, M. Chávez ${ }^{1}$, C. García ${ }^{1}$ e N. Mendoza ${ }^{1}$
}

\begin{abstract}
Resumo O fenômeno El Niño, que afetou o Perú em 1998, permitiu o crescimento de abundante vegetação em ambientes tradicionalmente secos. Paederus irritans, coleóptero que produz dermatite ao ser esfregado na pele, encontrou aí um substrato muito favorável ao incremento de sua população. A chegada das chuvas nos meses de fevereiro a abril de 1999 interferiu no hábitat desse inseto, que migrou inclusive para áreas urbanas, condicionando maior exposição da população humana de Piura, no norte do país, ao contato com esse agente. Entre fevereiro e maio de 1999 foram notificados em Piura 1.451 casos da dermatite por Paederus irritans, aí denominada latigazo dado o aspecto característico das lesões, eritematosas, lineares, semelhantes a chicotadas, por ele produzidas na pele por ação da pederina. As áreas do corpo mais afetadas foram a cabeça $(56,6 \%)$ e o pescoço (30,9\%), mas houve casos de conjuntivite e até de lesões genitais devidas à contaminação pelas mãos.
\end{abstract}

Palavras-chaves: Dermatite epidêmica. Paederus irritans. Perú. Fenômeno El Niño. Surto.

Abstract The phenomen El Niño that affected Peru at 1998, made possible the growth of copious vegetation in traditionally dry places. On this way, Paederus irritans, dipterous of the order Coleoptera that produces dermatitis when croushed on the skin, found substract that allowed the natural growth of its population. The coming of occasional rains on the months of February to April 1999, attacked the habitat of this insect, that looked for urban areas, exposing seriously the general population of Piura on north Perú to the contact. During February and May 1,451 cases of dermatitis caused by Paederus irritans, called latigazo because of its linear and eritematous characteristic lesions on the skin, were notified at Piura. The more affected body areas were head (56.6\%) and neck (30.9\%), but there were also cases of conjunctivitis and genital injuries, because of hands contamination.

Key-words: Epidemic dermatitis. Paederus irritans. Perú. El Niño phenomenon. Outbreak.

Antecedentes epidemiológicos. No verão de 1998 , a ocorrência do fenômeno EI Niño (ENSO) incrementou as chuvas em todo o norte do Perú, ocasionando profundos danos à infra-estrutura viária, à produção agrícola e as moradias dos habitantes da região. Condicionou, também, o crescimento de abundante vegetação, em áreas tradicionalmente secas. Essas alterações na Ecologia afetaram as populações animais no seu ambiente natural ${ }^{1}$. No caso dos artrópodos, a maioria encontrou condições favoráveis ao incremento de sua população, devido ao desenvolvimento de abundante vegetação. $O$ hábitat de alguns insetos foi consideravelmente alterado, de forma a propiciar sua migração para áreas urbanas, provavelmente atraídos pela iluminação elétrica, condicionando maior exposição humana ao contato com espécies causadoras de acidente por contato.

Outros animais foram também afetados em diferentes lugares ${ }^{9}$. No caso dos roedores, por exemplo, as alterações ecológicas resultaram em destruição de suas moradias, levando-os a uma aproximação do ambiente humano, contribuindo para um maior risco de doenças por eles transmitidas ${ }^{16}$. Estes animais no tempo de chuva acercam-se da área peridomiciliar à procura de alimento e, quando terminam as chuvas, retornam para os campos, coincidindo com a época da safra ${ }^{1}$.

1. Dirección de Epidemiologia, DISA Piura, 2. Oficina General de Epidemiología, Lima, Perú.

Endereço para correspondência: Dr. Victor Alva Dávalos. Oficina General de Epidemiología do Ministério de Salud del Perú. Camilo Carrillo 402, Lima, Perú. Fax: (01) 433-0081.

e-mail:valva55@hotmail.com/alaguna@oge.sld.pe

Recebido para publicação em 11/10/2000. 
Em fevereiro e março de 1999 a chegada de chuvas intensas alterou o equilíbrio ecológico no Perú. Habitualmente, nas áreas costeiras não há chuva em época alguma, enquanto na serra chuvas constantes se apresentam nos meses de dezembro a março.
O Perú encontra-se dividido, politicamente, em Departamentos. Piura é um Departamento situado ao norte do país (Figura 1) e foi nessa localidade que se registrou o surto de uma dermatite epidêmica denominada latigazo, ocasionada por um coleóptero ${ }^{10}$.

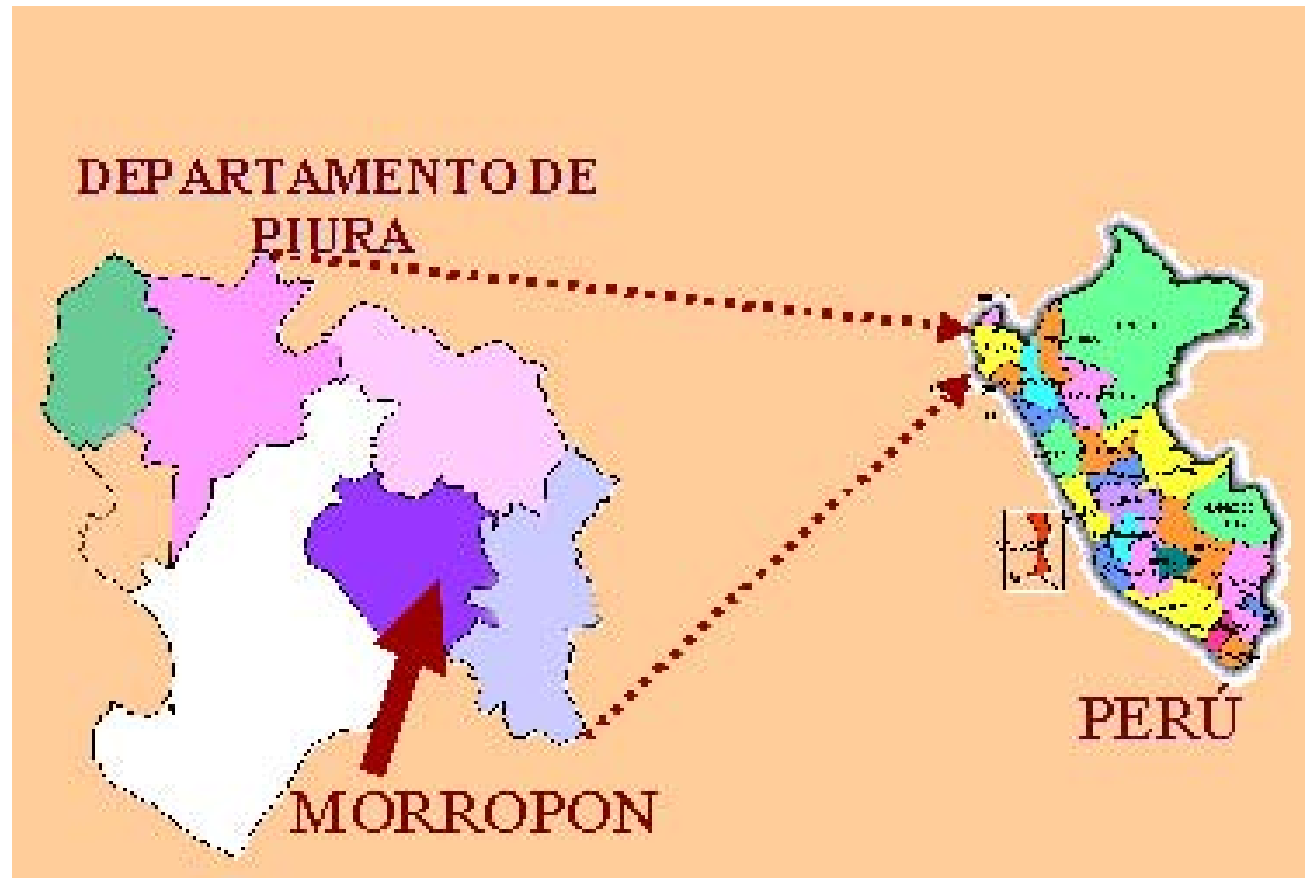

Figura 1 - Localização da Província atingida pelo Surto, Piura, Perú.

\section{O ENSO atingiu Piura ocasionando danos} numerosos.

O Departamento de Piura compreende sete províncias e uma população estimada de 1.365.765 habitantes, em 1999. A Província de Morropón tem 120.000 habitantes e nela se encontram os distritos de Chulucanas e Salitral, mais atingidos pela dermatite. Já na jurisdição da Província de Huancabamba encontra-se o Distrito de Canchaque, também dos mais atingidos.

Características da área do surto. A Província de Morropón tem 13 Distritos, situados a uma altitude entre 500 e 2.300 metros acima do nível do mar. Todos os Distritos dessa Província, onde ocorreram casos de dermatite epidêmica, situam-se abaixo de 500m de altitude. O clima é semelhante em todos esses Distritos, só ocorrendo chuvas ocasionais nos meses de verão (dezembro a março), o que, coincidindo com a enchente dos rios que descem a serra, permite o surgimento de amplas superfícies de cultivo no vales de Serrán, Salitral, Bigote, Buenos Aires e Chulucanas, que formam parte de uma mesma bacia hidrográfica. Também faz parte dessa bacia o Distrito de Canchaque, pertencente a outra Província, Huancabamba. Este distrito encontrase a 1.500 metros acima do nível do mar e foi também atingido pelo surto de dermatite.
Características da dermatite por Paederus irritans. O responsável pelo surto é um inseto da ordem Coleoptera, família Staphylinidae, gênero Paederus ${ }^{4}$ e da espécie $P$. irritans, conhecido como yuyi, ou zorrito. Tem o corpo alongado, cor geral negra, tórax subglobular, élitros curtos e de coloração azul-escura muito brilhante. A fêmea alcança $10 \mathrm{~mm}$ de comprimento e o macho $9 \mathrm{~mm}^{4}$. Esses insetos encontram-se, freqüentemente, na vegetação dos vales situados entre 600 e 900 metros acima do nível do mar, na costa norte do Perú ${ }^{15}$. Essas áreas apresentam elevada umidade e grandes oscilações de temperatura durante o dia e à noite.

Latigazo (= chicotada, em português) é o nome popular da dermatite produzida por este coleóptero, que secreta uma substância cáustico-vesicante, a pederina, uma toxina cristalina (C25H45N09), responsável por irritação semelhante a uma queimadura. A dermatite é conhecida como pederose em Irá ${ }^{11}$, onde apresenta alta prevalência, sendo o Paederus aí chamado de aranha de drácula ou balalus. Mais certo, porém, será denominá-la pederismo.

O gênero Paederus foi descrito pela primeira vez por Pirajá da Silva, em $1912^{14}$, no Brasil, onde o inseto é conhecido pela denominação vulgar de potó ${ }^{316}$. 
A lesão é produzida quando o inseto é acidentalmente esfregado sobre a pele, quase sempre durante o trabalho de campo. Ou simplesmente quando tocados enquanto caminham

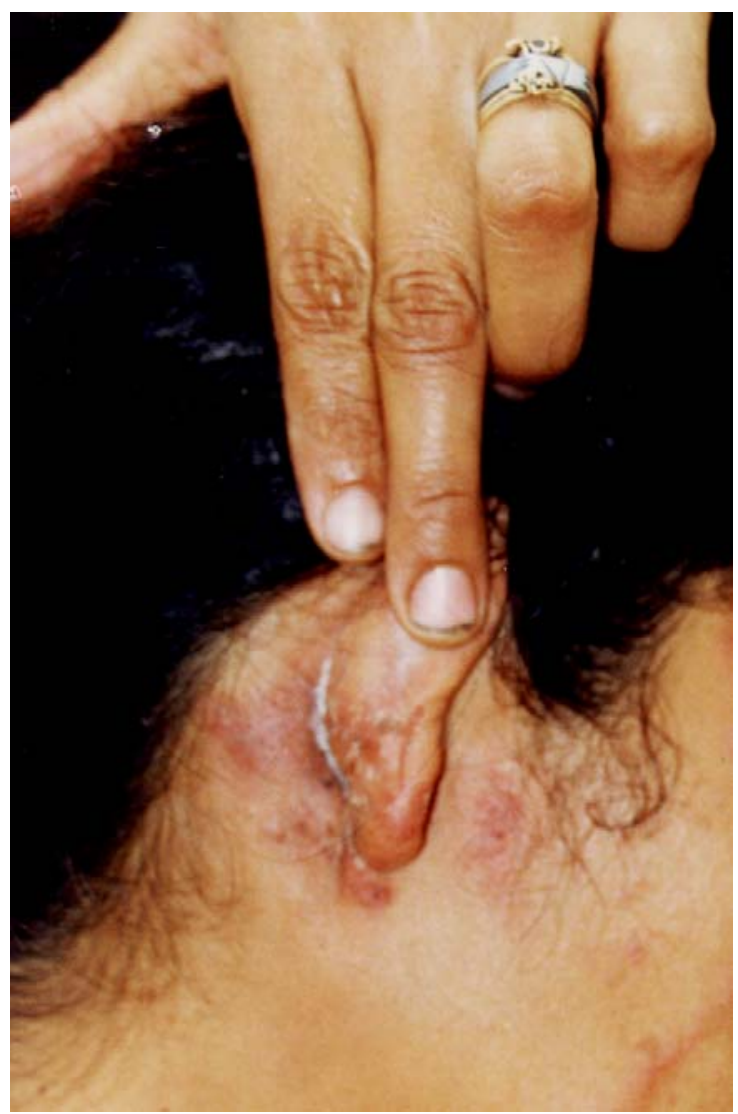

Figura 2 - Mulher de 31 anos com múltiplas lesões lineares na face, já com infecção secundária (piodermite retroauricular).

Em contato com a pele a pederina (paederina, em castelhano) tem propriedades cáustico-vesicantes, provocando eritema, necrose epidérmica e vesiculação após 24-48 horas. Ela é liberada pelo inseto quando agredido ${ }^{313}$.

Aproximadamente, 8 a 10 horas após o contato inicial surge uma lesão eritematosa e nas 48 horas seguintes o paciente acusa sensação de queimadura e prurido ${ }^{15}$, muitas vezes apresentando dermatites lineares de até $15 \mathrm{~cm}$ de comprimento, semelhantes a chicotadas. Correspondem às áreas da pele por onde o inseto foi arrastado, quando da coçadura. Após 48 horas do início do eritema aparecem vesículas e bolhas que crescem, gradualmente e, dois dias depois, se umbilicam. Seis a oito dias depois do contato com o inseto as vesículas e bolhas esfoliam, deixando escaras pigmentadas que persistem por 20 a 60 dias (Figuras 4 e 5).

As lesões podem condicionar limitação funcional na área afetada. A mão pode ser o veículo do líquido tóxico sobre a pele, liberando a substância irritante que produz ardor, eritema e, posteriormente, vesiculação que quase sempre segue um trajeto linear ${ }^{3}$ (Figuras 2 e 3).

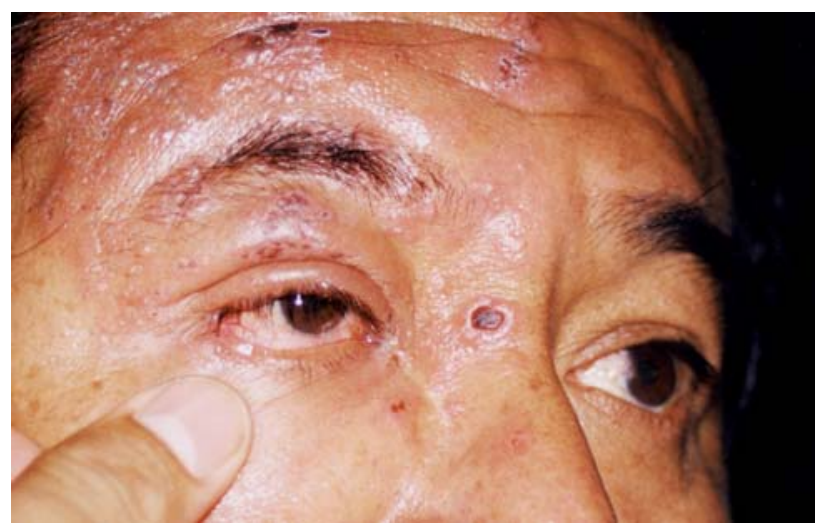

Figura 3 - Paciente com lesões vesiculadas que se assemelham às do herpes zóster.

para a mucosa ocular, determinando lesões de conjuntivite ${ }^{4}$ e/ou blefarite ${ }^{3}$. Localmente os sintomas são exacerbados pelo sol, pelo calor, suor e contato com as roupas. Curam ao longo de várias semanas, deixando cicatriz escura.

Ao estudo anátomo-patológico, observa-se a formação de bolhas intra-epidérmicas multiloculares, com necrose da epiderme ${ }^{2}$. O espectro das lesões histopatológicas pode ir desde necrose aguda da epiderme até marcada acantose, com figuras mitóticas em estádios terminais. A presença de focos acantolíticos distantes da lesão sugere que a pederina pode induzir, indiretamente, esse processo.

Para o tratamento utiliza-se o sulfato de magnésio, creme de Darier (partes iguais de talco, óxido de zinco, glicerina, água e corticóides) ${ }^{4}$. Algumas vezes, em presença de infecção secundária, faz-se necessária a administração de antibióticos (dicloxacilina, ampicilina).

Há experiências ${ }^{2}$ com a planta medicinal denominada coentro (Coriandrum sativium) ${ }^{8}$, triturada e aplicada sobre as áreas cutâneas afetadas. Segundo alguns autores o emprego dessa erva no início dos sintomas melhora a sensação de ardor ou queimação, diminui a gravidade do quadro e reduz o tempo de evolução da dermatite. Também já houve experiência com compressas úmidas de soro fisiológico ou permanganato de potássio a 1:40.000 ou 1:50.000, na fase aguda, e cremes com corticóide associado à neomicina, na fase subaguda ${ }^{3}$.

No Departamento de Piura têm-se apresentado, ocasionalmente, casos de latigazo nos meses de verão. Nos Distritos com áreas de cultivo, o Paederus irritans é conhecido como habitante natural dessas áreas cultiváveis. Nenhuma delas, entretanto, havia sido antes atingida de forma epidêmica. $E$ em muitos Distritos foi esta a primeira experiência com tal patologia. 

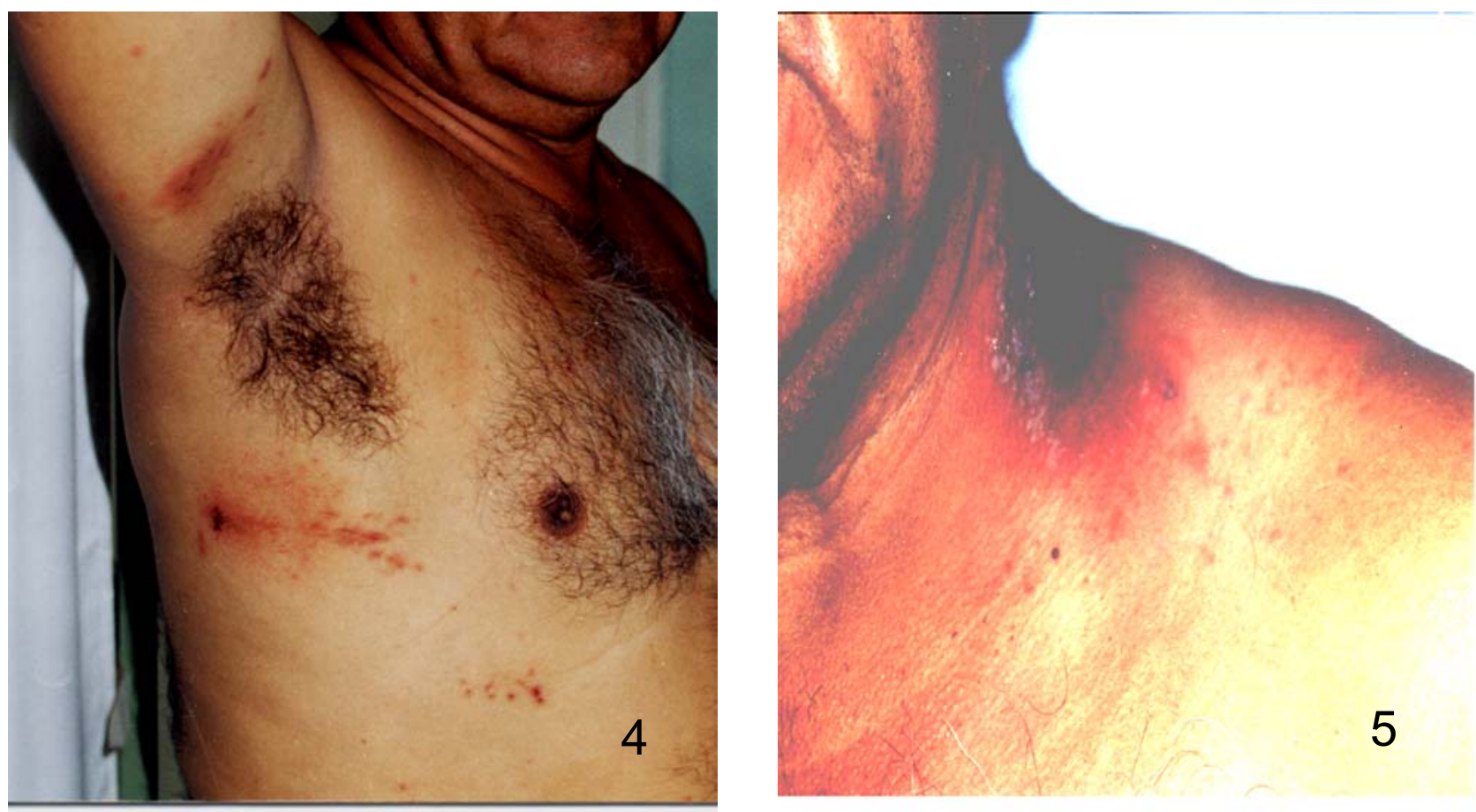

Figuras 4 e 5 - Lesões em diferentes estádios de evolução em paciente atingido pelo pederismo em Piura, Perú.

\section{MATERIAL E MÉTODOS}

Inicialmente, para determinar a taxa de ocorrência do acidente foi feita uma rápida avaliação na primeira semana do surto, numa amostra de 50 moradias. Nessa avaliação os lugares atingidos foram visitados para coleta de dados clínico-epidemiológicos, de tal forma que antes de 48 horas já se dispunha de uma boa noção da realidade da situação.

Os dados utilizados neste estudo descritivo longitudinal foram obtidos a partir dos registros do Sistema de Vigilância Sanitária da Dirección de Salud de Piura I (DISA PIURA I), que notificou o surto como de uma Dermatite por Contato.

O diagnóstico da afecção foi clínico-epidemiológico, baseado numa definição de caso criada na ocasião: Presença de eritema doloroso, com ou sem presença de vesículas (flictenas), de início brusco e localizado principalmente em áreas do corpo expostas, em pacientes procedentes dos Distritos afetados, no período de fevereiro a maio. Em todos os casos registrados, o antecedente de contato com Paederus foi indagado. Todos foram notificados como de dermatite epidêmica.

Para a coleta de dados utilizou-se uma ficha clínicoepidemiológica. A extensão do surto e a dificuldade de acesso a estabelecimentos de saúde, dada a intensidade das chuvas que danificaram os caminhos, impediram a distribuição de fichas epidemiológicas a alguns desses estabelecimentos. Foram colhidos dados de 259 pacientes que vieram em busca de atendimento médico. A seleção foi feita aleatoriamente e de forma não sistemática. Inicialmente foi feita uma avaliação rápida para estimar a taxa de ataque nos lugares mais afetados.

\section{RESULTADOS}

Na semana epidemiológica (SE) 06 do ano de 1999, na Província de Morropón, Departamento de Piura, Perú, registrou-se um surto epidêmico de dermatite por Paederus irritans. Foram notificados e atendidos 1.451 casos em diferentes estabelecimentos de saúde de 13 Distritos (Tabela 1). O maior número de casos foi registrado na primeira semana do surto. A maior taxa de ataque determinada pelo método de avaliação rápida na primeira semana foi de $73,7 \%$, no povoado de Bigote.

Pessoas da faixa etária entre 15 e 64 anos foram mais $(60,5 \%)$ afetadas . O sexo masculino representou $46,7 \%$ e o feminino foi atingido em $53,3 \%$.
Os motivos de consulta dos pacientes foram: prurido intenso $(48,1 \%)$, ardor $(33,3 \%)$ e dor local $(13,2 \%)$.

As manifestações clínicas mais freqüentes foram: ardor $(90,7 \%)$, prurido $(81,9 \%)$, eritema $(60,6 \%)$, dor $(51,4 \%)$ e bolhas $(40,2 \%)$. Observaram-se lesões maculares extensas em $68,3 \%$ dos casos. A lesão foi única em $42,4 \%$ dos pacientes e dupla ou tripla em $44 \%$. As áreas do corpo mais afetadas foram a cabeça e o pescoço (Tabela 2 ), sendo que $69,5 \%$ das lesões se apresentaram em áreas expostas.

Três pacientes apresentaram lesão na genitália (Figura 6) e um deles teve comprometimento da 
Tabela 1 - Distribuição do número de casos de dermatite por Paederus irritans nos três Distritos mais afetados. Piura, 1999.

\begin{tabular}{lccc}
\hline & \multicolumn{2}{c}{ Casos (1451) } & Taxa de incidência \\
\cline { 2 - 3 } Distrito & $\mathrm{n}^{\circ}$ & $\%$ & x 1000 habitantes \\
\hline Chulucanas & 417 & 28,7 & 5,24 \\
Canchaque & 208 & 14,3 & 19,07 \\
Salitral & 238 & 16,4 & 24,67 \\
\hline
\end{tabular}

conjuntiva ocular (Figura 7). Quanto à profissão, 31,7\% dos afetados eram do lar, $24,3 \%$ estudantes, $12 \%$ crianças e $8,1 \%$ agricultores. No que diz respeito ao

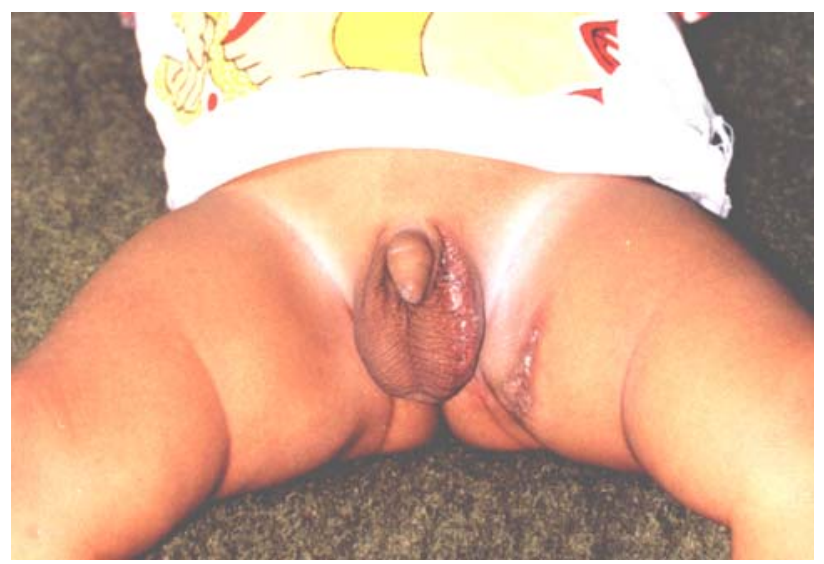

Figura 6 - Criança com lesões genitais.

momento do contato, $52,5 \%$ perceberam a lesão ao acordar, pela manhã. No que diz respeito ao conhecimento da causa da lesão, $53,3 \%$ dos pacientes
Tabela 2 - Distribuição das lesões de dermatite por Paederus nos casos observados em Piura, 1999.

\begin{tabular}{lc}
\hline Área comprometida & Porcentagem \\
\hline Cabeça & 56,6 \\
Pescoço & 30,9 \\
Braços & 23,9 \\
Pernas & 19,3 \\
Olhos e região periorbital & 17,0 \\
Bochechas & 15,4 \\
Dorso & 15,4 \\
\hline
\end{tabular}

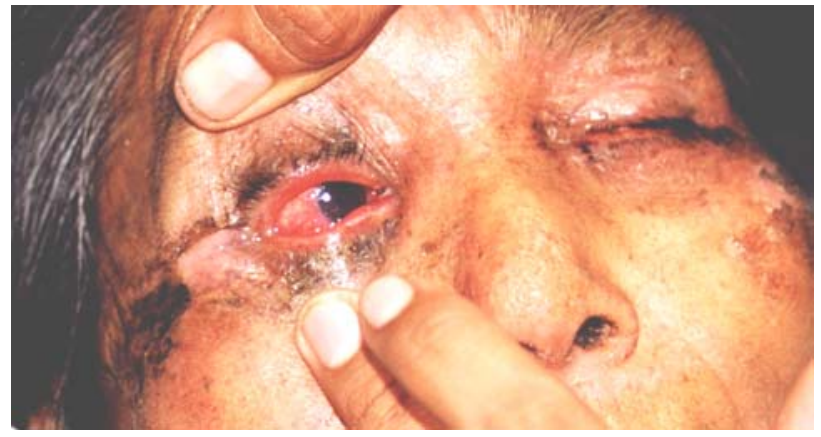

Figura 7 - Mulher de 65 anos com irritação conjuntival decorrente do contato da mucosa com a pederina.

não sabiam a que atribuí-la. Dos indivíduos afetados, $41,2 \%$ eram provenientes de área urbana e $48,6 \%$ provinham de área periurbana.

\section{DISCUSSÃO}

Este artigo relata um evento relacionado às alterações climáticas conseqüentes ao fenômeno $E I$ Niño (ENSO), que prevalecem por longo período após as precipitações pluviais que o caracterizam.

Surtos explosivos de dermatite por Paederus, com altas taxas de ataque e comprometimento maciço de populações urbanas, têm sido associados a esse fenômeno.

A série de casos registrados em Piura representa uma das maiores já registradas na literatura médica concernente ${ }^{311} 15$

As alterações ecológicas propiciam o aparecimento de quadros inusitados, epidêmicos, nas áreas atingidas. Na literatura existem relatos de séries de casos atingidos por outras espécies do gênero Paederus.

Esta zoodermatose, já conhecida em diferentes lugares da América do Sul ${ }^{3}$, da África ${ }^{11} \mathrm{e}$ de outros continentes, apresentou-se de forma epidêmica numa região não habituada a chuvas intensas e onde a vegetação é, normalmente, bastante pobre. O Norte do Perú e outros países vizinhos foram então atingidos por várias situações consideradas como de emergência sanitária, tais como surtos de peste bubônica ${ }^{1}$, de golpe de calor (febre térmica, insolação, heat stroke) em crianças, cólera, malária-falciparum e, em novas áreas, leptospirose ${ }^{12}$ e tifo murino. Além das situações provocadas pelas chuvas e enchentes que destruíram casas, estradas e pontes, houve que atender a todas essas emergências, que exigiram do sistema de saúde peruano rápidas respostas e soluções adequadas, a fim de evitar maiores complicações sanitárias na população.

É muito provável a ocorrência efetiva de um número maior que os 1.451 casos notificados. As altas taxas de ataque estimadas por métodos de Avaliação Rápida Epidemiológica (afetando em alguns povoados até $73,7 \%$ da população) traduzem um grande sub-registro, provavelmente devido à pouca procura dos serviços de saúde, principalmente dos casos leves ou que não tiveram acesso ao postos devido aos desastres naturais, ou ainda que tiveram de atender a dificuldades ainda maiores, como a perda da moradia.

A maioria $(52,5 \%)$ dos pacientes atingidos percebeu a lesão ao acordar, pois o inseto é atraído pelas luzes das lâmpadas fluorescentes e, quando estas são apagadas, o inseto cai sobre as pessoas, atingindoIhes as áreas mais expostas (rosto, pescoço, braços). Embora 53,3\% dos atingidos não se tenham dado conta da causa da lesão, esta não deixou dúvida quanto à sua etiologia, por suas características. 
Em alguns lugares onde esta zoodermatose se apresenta com muita freqüência, aconselha-se como medida de controle a troca das lâmpadas fluorescentes por incandescentes ${ }^{11}$, além da eliminação da vegetação nas áreas periurbanas, fatos que presumivelmente reduzem a possibilidade de contato entre o homem e o inseto. Nessa epidemia, porém, estas medidas não eram viáveis, pois havia múltiplas emergências sanitárias a ser, de pronto, atendidas.

A população mais afetada era proveniente de áreas periurbanas $(48,6 \%)$ que tinham relação com áreas agrícolas. Mas uma grande percentagem dos pacientes era de área urbana $(41,2 \%)$. Isto mostra que grande parte da população de insetos migrou para os povoados em conseqüência da alteração ecológica decorrente da abundância das chuvas. $O$ diagnóstico da dermatite de contato por Paederus foi baseado em dados clínicos e epidemiológicos, não sendo necessário recorrer a métodos. Particularmente, o herpes simples e o zóster representam algumas das condições clínicas que devem ser consideradas no diagnóstico diferencial desta dermatite. Para isto, pode-se recorrer à citologia da bolha, método de Tzanck, que oferece altas possibilidades de diagnóstico das infecções virais ${ }^{37}$.

Em situações não epidêmicas, a biópsia tem interesse acadêmico e serve para afastar outras causas que possam trazer dúvida diagnóstica, tais como o pênfigo foliáceo, farmacodermia e outras dermatites (seborréica, de contato) ${ }^{23}$.

No que diz respeito aos dados clínicos, destaca-se a localização em áreas expostas da pele, embora em alguns casos tenham ocorrido lesões genitais, por contaminação através das mãos.

Este surto representa um exemplo a mais das alterações ecológicas que o fenômeno El Niño ocasionou no Perú e em países vizinhos ${ }^{169}$.

\section{REFERÊNCIAS BIBLIOGRÁFICAS}

1. Alva-Dávalos V, Arrieta M, Olguín C, Laguna-Torres VA, Pun M. Surto de Peste bubônica na localidade de Jacocha, Huancabamba, Perú. Revista da Sociedade Brasileira de Medicina Tropical 34: 87-90, 2001

2. Borroni G, Brazzelli V, Rosso L, Pavan M. Paederus fuscipes dermatitis: a histopatological study. American Journal of Dermatology 13: 467-474, 1991.

3. Diógenes MJ. Dermatite de contato pela pederina, estudo clínico e epidemiológico no Estado do Ceará, Brasil. Revista do Instituto de Medicina Tropical de São Paulo 36: 59-65, 1994.

4. Elliot A, Cáceres I. Introducción a la parasitología médica del Perú. Consejo para la Ciencia y Tecnología CONCYTEC, Perú, 1988.

5. Frank JH, Kanamitsu K. Paederus sensu lato (Coleoptera: Staphylinidae): natural history and medical importance. Journal of Medical Entomology 24: 155-191, 1987.

6. Gabastou JM, Proaño J, Vimos A, Jaramillo G. Hayes E, Gage K, Chu M, Guarmer J, Zaki S, Bowers J, Guillermard E, Tamayo $\mathrm{H}$, Luiz A. An outbreak of plague including cases with probable pneumonic infection, Ecuador, 1998. Transactions of The Royal Society of Tropical Medicine and Hygiene 94: 387-391, 2000.

7. Grossman MC, Silvers DN. The Tzanck smear: can dermatologist accurately interpret it? Journal of The American Academy of Dermatology 27: 403-405, 1992.

8. Matos FJA Plantas medicinais; Guia de seleção e emprego de plantas medicinais no Nordeste do Brasil. Fortaleza, Imprensa Oficial da Universidade Federal do Ceará, 1989.
9. Meserve PL, Yunger JA, Gutierrez JR. Heterogeneous responses of small mammals to an El Niño southern oscillation event in the northcentral semiarid Chile and the importance of ecological scale. Journal of Mammalogy 76:580-595, 1995.

10. Ministerio de Salud Perú. Dermatitis por Paederus irritans. Oficina General de Epidemiología. Reporte epidemiológico semanal de la Semana Epidemiológica 07, 1999.

11. Nikbakhtsadeh MR, Sadeghiani $C$. Dermatite due à deux espéces de Paederus au sud de L'Iran. Bulletin de la Société de Pathologie Éxotique 92:56, 1999.

12. Pachas P, Cjuno R, Portugal M, Taboada B. Felices V. Laguna-Torres VA. Seroprevalencia de leptospirosis en Humanos y Reservorios en la localidad de Koribeni, La Convención, Cusco, Perú. Revista Peruana de Enfermedades Infecciosas y Tropicales. 1: 87-91, 2001.

13. Penchenier L, Mouchet J, Cros B, Legall P, Cosnefroy JY, Quezade P. Chandenier J. Invasions of Paederus sabaeus (Coleoptera: Staphylinidae) in Central Africa. 1 Entomological and epidemiological aspects. Bulletin de la Société Pathologie Éxotique 87:45-48, 1994.

14. Pirajá da Silva M. Le Paederus columbinus est vésicant. Archives de Parasitologie 15:429-431, 1912.

15. Tincopa L, Valverde J, Agip H, Cárdenas A Características clínicas e epidemiológicas del brote epidemico de dermatitis de contacto por Paederus irritans. Dermatologia Peruana 9:24-26, 1999.

16. Vasconcelos W. Dermatozoíases em um imenso país tropical. Anais Brasileiros de Dermatologia 54:87-103, 1979. 